\title{
Construction and Development of Blended Teaching Model in the Context of COVID-19-Taking English Teaching as an Example
}

\author{
Wenjun $\mathrm{Lv}^{1, *}$

\begin{abstract}
${ }^{I}$ Department of Foreign Languages and Literature, Tianjin University of Commerce Boustead College, Tianjin, China
\end{abstract} \\ *Corresponding author. Email: 122106887@qq.com
}

\begin{abstract}
Under the background of COVID-19, colleges and universities have responded to the call of the Ministry of Education to "Suspended without suspension". English courses have also adopted the online teaching model or a combination of online and offline models. With the development of modern information technology, the overall level of teaching development in China is also gradually improving, and the effective integration of the two is an important choice for the road of education development. In the context of this epidemic, the support of the Internet and information technology has played a great role. Many emerging network teaching models have been applied in English classes, which combine with the traditional teaching model and become the blended teaching model. The reasonable application of the blended teaching can absorb the advantage of two kinds of teaching mode to enhance interaction between teachers and students in blended teaching mode, while cultivate students' autonomous learning ability under the circumstances of the epidemic to fulfill "Suspended without suspension". The improvement of student learning and the enhancement of English teaching has a certain significance.
\end{abstract}

Keywords: COVID-19; Blended Teaching Model; Interactive Behavior; Combination of Online and Offline

Study

\section{INTRODUCTION}

Due to the impact of COVID-19, colleges and universities across the country have postponed the opening of their classes. The Ministry of Education requires colleges and universities to do a good job in the organization and management of online teaching, and effectively carry out the "Suspended without suspension". The severe practical situation puts forward new requirements for college English courses. In this special period, blended teaching mode plays a certain role in English teaching and learning. Based on "Tencent Meeting + WeChat+ Treenity" three platforms, from the creation of teaching resources, innovation of teaching activities, and establishment of the teaching evaluation, the construction of new college English online teaching mode provides the reference for the effective implementation of online teaching, so as to better promote the combination of college English online and offline classes over the pandemic year.

\section{THE DEVELOPMENT OF BLENDED TEACHING MODEL}

The development of blended teaching model is inseparable from the development of Internet and information technology. Cai Qixian first proposed the "Blended Intelligent Remote System Model" and introduced its characteristics, composition and technologies in his journal "Web-based Remote Teaching: Discussion on a New Teaching Model" published in 2002, which played a pioneering role in the development of the blended teaching model (Cai, 2002: 288-290). Tian Fupeng pointed out that "the core of blended learning is to combine the advantages of traditional classroom teaching and E-learning to effectively improve the learning effect of students." (Tian, 2005: 63-65). Yu Xizhen believes that "combining teacher-centered foreign language teaching with student-centered foreign language teaching, integrating or mixing various theories and methods, is one of the effective ways to adapt to the external environment and promote college foreign language teaching in China.College foreign language teaching should adopt the combination of dominant and main body, and highlight the blended teaching mode that combines the advantages of traditional teaching methods with the convenience of digital or network learning."'(Yu, 2007:139-141)

The earliest blended teaching mode is based on "Moodle"(a platform) to complete, for example, Chen Shengjian and Ma Weiqi introduced the concept of blended teaching and network teaching advantages, characteristics and functions of the software in their paper "Research on Blended Teaching Model: based on the software Moodle"(Chen, Ma, 2007:55-60). Along with the 
development of network technology, blended teaching mode is more complete and diverse. In the study, we found that this kind of teaching model applies to all areas. Meanwhile, with the teaching platform is increasingly diversified and convenient, such as: Chao Xing, Treenity, Rain Classroom, etc. the interaction of network learning that online learning interaction also gradually accepted by teachers and students. Xing Xiangyu and Cheng Fang's paper "Research on College English Blended Teaching Model Based on Rain Classroom -- A Case Study of Nanyang Normal University" explores the effect and feasibility of the blended teaching mode based on rain classroom in college English class, and finally determines that this blended teaching mode has a high degree of acceptance, and this blended teaching mode can effectively improve students' reading performance (Xing, Cheng, 2021:83-85). It is a pandemic year in 2020, while ordinary teaching mode has been unable to proceed normally. Yao Lingzhi points out that under the background of epidemic online teaching mode became the mainstream which can support the new forces of teaching development. As domestic epidemic was under control, as well as various universities gradually got resumption, the ecological teaching mode has quietly changed of college English teaching. The traditional teaching mode transformed into blended teaching mode by changing the offline to online teaching method or the combination of them. It is a challenge to the relationship between teachers and students and a innovation to the development of college English teaching mode (Yao, 2020:231-232). During the epidemic period, the online teaching mode we adopted was reluctant. However, after the epidemic under control, our recognition of this new teaching mode also promoted the development of the blended teaching model, which reflected the advantages of this mode from one side.

\section{THE INTERACTIVE BEHAVIOR OF THE BLENDED TEACHING MODEL}

The interactive behavior in blended teaching includes the traditional classroom teaching interactive behavior, and also includes the interactive behavior of network learning, that is, online and offline learning interactive behavior. There are four kinds of interactive behaviors based on the blended teaching mode. First, the interactive behaviors between teachers and students. Mainly including, students through the network platform to submit homework to teachers, or exchange and ask questions, and then teachers use the network platform to feedback students' homework completion, or answer students' questions. Second, the interaction between students. Specifically, students use the Internet communication platform to discuss English content and ask questions about English knowledge. At the same time, when students see other students discussing problems or asking questions, they should actively participate in them or answer questions patiently. Third, the interaction between students and network teaching resources. This aspect mainly includes that students need to carefully read the feedback provided by the English learning website or the school learning system and answer the questions when they use the English learning website or the school learning system to learn English. Fourth, the interaction between students and the outside world. This includes whether students browse other learning websites when they are learning English online. Of course, students may suffer from some negative effects when they are learning online. At this time, teachers' correct guidance or parents' supervision and supervision are needed to give full play to the positive significance of online learning.

\section{CONSTRUCTION OF MIXED TEACHING MODEL UNDER COVID-19}

The development of science and technology has brought abundant digital resources for college English teachers, and various English listening websites, news websites and comprehensive websites have provided abundant extracurricular resources for college students with different basic English levels. Teachers can also publish assessment plans, unit guidance, electronic lecture notes, online tests, online discussions, etc. Through the teaching platform, students can prepare lessons in advance, discuss the topics published by the teachers, communicate with the teachers online if they don't understand the problems, and upload course assignments after class. Teachers can also answer questions, mark homework and understand students' problems at any time through the teaching platform. All online interaction records will be automatically saved for teachers and students to consult at any time.

Under the influence of COVID-19, our school carried out mixed teaching plan based on the three platforms of "Tencent Meeting + WeChat+ Treenity", and the whole system is very perfect. With Treenity as the main teaching platform, the teaching content is completed by establishing classes, uploading materials, broadcasting lectures, classroom interaction, after-class tasks, examination and evaluation and other links. At the same time, in order to deal with network emergencies, Tencent conference sharing teacher screen is adopted for alternative teaching. The WeChat group is used to connect with students, interact and share information in a network emergency situation.

\subsection{Establishment of Online Resources}

During the epidemic, many students did not have textbooks at home, which made it difficult to teach online. However, under the network era, a lot of publishers still do more perfect. Take FLTRP for example. Many of their textbooks are available electronically on FLTRP platform, and they are also open to the public for free during the epidemic. At the same time, materials such as slides and documents made by teachers themselves can be uploaded to resource management of the platform, or high-quality courses of Wisdom Tree platform can be selected for 
students to make supplementary materials or use in flipped class.

\subsection{Establishment of Online Classes}

It is also easy to set up courses and classes on the platform. Create a flipped course, and then the teaching administration will import the list of students into the class, or share the QR code of the class in the WeChat contact group. Everyone can scan the code into the class and modify their personal information. After the class is established, students can have a direct dialogue with the teacher through the platform, or interact and share their learning methods and experience in the class group chat.

\subsection{Live Class}

Design of online meeting sessions. Before the formal start of the class, we will organize the class to conduct teaching tests through Tencent conference to understand the class situation and the application of software. In the first class of online teaching, the learning block, learning progress plan and assessment plan of this semester will be published, and the students will be divided into groups, so as to ensure that each student has a specific task for each group activity. With the support of the platform, we can carry out live broadcasting, sharing the screen, asking questions randomly, answering questions quickly, answering bullet screens, voting, brainstorming, Q\&A interaction and other interactive modes, which provide a good support for our meeting class. In the online face-to-face teaching, the teacher first gives feedback to the problems existing in the pre-class preview and the solutions, then explains the key knowledge, sets up experiential exercises of relevant expression skills according to the knowledge points, and finally summarizes the knowledge and learning situation of this class by the teacher. In the face to face class, students showed more enthusiasm than the traditional offline teaching mode, and at the same time, the interest and efficiency of learning also improved.

\subsection{Assignments, Tasks and Exams}

The after-class learning link is mainly an extended experience of the skills learned in class, which is carried out through online tests or homework. The test forms should be diversified, and the expression skills and important knowledge points of each lesson should be comprehensively examined. Homework arrangement should strive for fine but not much, pay attention to the quality of homework, teachers can have a general understanding of the students' learning after correcting. Through the platform, students can not only assign traditional homework, but also have brainstorming discussions, or share video or audio tasks with students.
Mixed online teaching and after-class tasks combined online and offline enable students to no longer do repetitive and meaningless work, but learn knowledge from entertainment, complete after-class tasks in a way suitable for students, and better review the content explained in class.

\subsection{Learning Situation Data and Grade Evaluation}

Pay attention to formative assessment and evaluation. The process evaluation should be objective and fair, focusing on the comprehensive examination of students' listening, speaking, reading, writing and translating skills. The comprehensive evaluation should mainly be carried out from the aspects of online duration, online test, online homework, group report and performance, discussion area, classroom Q\&A and so on. During the learning process, at the end of each unit, the platform statistical data, such as online time, number of discussion forum participation, online test scores, etc. are sent to the class group to urge students to better complete the learning tasks. In the data analysis of students' learning situation, more objective, more intuitive, for the teacher's performance evaluation has a new understanding.

\section{CONCLUSION}

It can be seen from the above that, since the epidemic prevention and control, interactive behaviors in English teaching under the mixed teaching mode can be enriched, students' learning autonomy can be enhanced, the communication between teachers and students can be strengthened, students' comprehensive English ability can be improved, and thus the efficiency and level of English teaching can be improved. From the collected learning situation data, it is feasible to combine online and offline teaching mode. Of course, blended teaching mode still has some problems in English teaching, information teaching means are still not perfect, students' learning autonomy is not strong and other factors affect the smooth development of blended teaching mode in English teaching. To this end, we need support from multiple levels hybrid teaching mode, the school itself will improve the quality of teaching, perfect the evaluation system, and students to strengthen their autonomous learning ability, promote the promotion of hybrid interaction teaching mode, so as to improve students' English language using ability, improve the level of English teaching in China outbreak era and development.

\section{REFERENCES}

[1] Cai Qixian. Web-based Distance Teaching: Discussion on a New Teaching Mode [J] Computer Engineering, 2002, (01):288-290. 
[2] Chen Shengjian; MA Wei-qi. Research on Mixed Teaching Mode Based on Moodle [J] Journal of Qujing Normal University, 2007, (06):55-60.

[3] Tian Fupeng; Practice and exploration of mixed teaching mode in colleges and universities under information environment[J] Journal of Educational Research, 2005, (04):63-65.

[4] Xing Xiangyu; Cheng Fang. An Exploration of College English Mixed Teaching Model Based on Rain Classroom -- A Case Study of Nanyang Normal University [J] English Square, 2021, (08):83-85.
[5] Yao Lingzhi. The Analysis of College English Teaching Mode in the Post-epidemic Era [J] Fortune, 2020, (12):231-232.

[6] Yu, X. Z., The Integration of English Teaching Models [J] Journal of Foreign Language Studies, 2007, (02):139-141. 